\title{
Resistir ao produtivismo: uma ode à perturbação Acadêmica $^{1}$
}

\author{
Resist to productivismo: a song to academic disturbance
}

Rafael Alcadipani

Chamamos de produtivismo uma ênfase exacerbada na produção de uma grande quantidade de algo que possui pouca substância, o foco em se fazer o máximo de uma coisa "enlatada", com pouco conteúdo e consequente valorização da quantidade como se fosse qualidade. Em nossa breve intervenção neste espaço, queremos falar dos efeitos do produtivismo acadêmico em dois âmbitos: na formação dos alunos na graduação e no mundo da pesquisa.

\section{Formação de Alunos}

Um dos efeitos do produtivismo ocorre na "base da pirâmide" (sem trocadilhos!) e na produção desenfreada de diplomados que pouco ou nada sabem. O número de matriculados no ensino superior cresceu $110 \% \mathrm{em}$ dez anos, e a Administração é o curso com o maior número de matriculados (cerca de um milhão e cem mil alunos). Temos, no país, aproximadamente, 250.000 professores da área. Tão preocupados que estamos com a Capes, pouco olhamos para esta realidade. Já em 1999, em parceria com o amigo Ricardo Bresler, escrevi um artigo intitulado A McDonaldização do Ensino (ALCADIPANI e BRESLER, 1999). No texto, comentávamos sobre a expansão das faculdades-negócio e da inserção da lógica fordista no mundo acadêmico. Hoje, há um grupo educacional brasileiro que está para se transformar na instituição de ensino superior com o maior número de alunos do mundo. Tal grupo vende ensino minimizando "inputs" e maximizando "outputs" (diplomados). Cursos enlatados, professores mal remunerados, livros-texto de baixa qualidade a rodo. O grupo educacional em questão mostra que o Brasil virou o paraíso das escolas fast food e que estamos produzindo à baciada bacharéis em administração sem a menor substância. Para se ter uma ideia, dia destes soube que um professor de um curso como este ganha cerca de R \$20,00 a hora-aula, poucos deles são CLT. Precisam dar muitas aulas para ter um salário que lhes forneça as mínimas condições. E, infelizmente, nestas condições, é impossível ser um bom professor e é impossível dar alguma formação para estes estudantes. Os fast foods do ensino "enchem a burra" com o dinheiro alheio vendendo diploma à prestação. Impera a lógica de mercado mais rasteira e mais nefasta possível. A maioria de nós assiste a isso sem muito falar. O processo se naturalizou. Na verdade, não se trata de fordismo aplicado à educação, pois, se fizesse carros como estas escolas formam os alunos, a Ford jamais teria sido uma empresa de sucesso,

\footnotetext{
1 Uma versão deste artigo foi apresentada no Painel denominado "Produtivismo Científico", no Encontro Nacional de Ensino e Pesquisa (EnEPQ), 20-22 de novembro de 2011, João Pessoa - PB, Brasil.

${ }^{2}$ PhD em Business Administration pela Manchester Business School, the University of Manchester; Professor Adjunto da Fundação Getulio Vargas. Endereço: FGV/EAESP, Avenida Nove de Julho, 2029, Bela Vista, CEP 01313-902, São Paulo - SP, Brasil. E-mail: rafael.alcadipani@fgv.br
} 
seus carros sequer andariam. A quem interessam tais cursos? Atendendo a quais interesses eles surgem e se multiplicam? O que é possível fazer para reverter o processo de mcdonaldização do ensino de administração? Como atender a forte demanda por cursos superiores no país sem vender um diploma à prestação? É urgente pensarmos nesta realidade e nestas questões. Algo com que nós como academia em Administração temos lidado muito pouco, apesar da importância do tema.

\section{Produtivismo na Pesquisa na Área de Administração}

Dia destes, um aluno de doutorado confidenciou-me que possui 8 artigos submetidos a periódicos com qualificação de B3 para baixo. As regras de mensuração da produção acadêmica foram inseridas no nosso mundo como uma "vacina" contra a total falta de "controle" e de "avaliação de desempenho" da carreira acadêmica tradicional. Historicamente, o professor passava em um concurso e ponto final, nada mais precisava fazer para "provar" a que veio. Se produzisse, ótimo; se não o fizesse, também. Claro que assumimos aqui uma realidade de universidades públicas onde a pesquisa se desenvolveu tradicionalmente no Brasil. O gerencialismo invadiu a universidade com o intuito de dar mais transparência e criar um ambiente no qual seria possível separar os que trabalham para o benefício da universidade dos que não o fazem. Não podemos ser Poliana e deixar de considerar que muita gente passou a vida na universidade e não fez nada mais, nada menos do que usar toda a estrutura e a reputação da coisa pública para o benefício próprio. Muitos professores queriam estar na pós-graduação apenas pelo prestígio - estavam, de fato, cuidando de seus afazeres pessoais na forma de ensino para executivos e de consultorias. Também não podemos esquecer que muitos dos empresários da educação no Brasil, caso das universidades privadas, querem ganhar dinheiro à custa da péssima formação de alunos e da exploração de professores. Por isso, faz sentido que processos de avaliação sejam realizados pelo governo federal para garantir o mínimo de qualidade dos cursos.

O movimento contra os "usurpadores" da universidade e a tentativa de moralizar o ensino da pós-graduação ocorreram em um momento em que passávamos a viver na sociedade da auditoria (POWER, 1997). Trata-se da explosão da necessidade de se verificar que todos estão produzindo e mensurar todo tipo de produção. Assim, se por um lado havia a necessidade de criar uma forma de avaliação dos cursos de pós-graduação no país, por outro, o modelo gerencialista calcado na auditoria estava pronto e sendo amplamente utilizado. Juntaram-se o problema e a solução que criaram as regras atuais do produtivismo a que estamos submetidos.

Já fizemos uma crítica contra a invasão da lógica gerencialista no mundo universitário em artigo intitulado Academia e a fábrica de sardinhas em lata (ALCADIPANI, 2011). Argumentamos que o meio universitário foi invadido pela lógica gerencialista, o que gera muitas distorções, pois, em vez de produzir conhecimento, estamos enlatando sardinha em forma de papers. O aluno entra no mestrado e, antes de adquirir qualquer saber, já é obrigado a escrever artigos. Na maioria das disciplinas da pós-graduação em nossa área no país, exigem-se papers que são submetidos a encontros científicos da área. Um mestrando ou doutorando em Estudos Organizacionais escreve papers na área de Operações e vai a encontros científicos discutir a respeito do que não conhece nem tem o menor interesse em conhecer. Além disso, muitos professores pressionados a produzir em quantidade terceirizam a tarefa para seus alunos; assim, têm tempo disponível para ocupar cargos na burocracia acadêmica, dar consultorias, lecionar em especialização. Não se enganem: ser avaliado por produção em quantidade é ótimo para muitos que colocam os alunos para trabalhar. Aliás, raramente burocratas do sistema são pesquisadores competentes. O resultado é o que assistimos ano após ano nestes encontros: artigos fracos, discussões rasas, falta de inovação conceitual, argumentos pouco rigorosos, artigos metodologicamente pífios. O momento da formação do aluno de pósgraduação é sugado pela produção de artigos inúteis e inconsistentes. Como disse um amigo recentemente, há toda uma geração perdida, pessoas que não estão recebendo uma formação decente. Professores jovens, recém-doutores, já exibem Lattes com mais de 30 artigos publicados em periódicos - uma demonstração clara de que há muita coisa errada. Para dar conta da quantidade de artigos produzidos, não cessam de surgir supostos periódicos acadêmicos que servem única e exclusivamente para escoar as irrelevâncias mal escritas 
que fazemos. E o pior: se respaldados por associações acadêmicas, os periódicos podem ainda ser bem classificados no Qualis. Estamos criando uma imitação de academia e uma fábrica de irrelevâncias.

Por esta lógica, o que vale é a pontuação e não a produção do conhecimento. A quantidade de artigos vira sinônimo de qualidade. Professores que dedicaram uma vida à orientação de alunos, à formação de um campo de conhecimento são ceifados dos programas de pós-graduação. Com 34 anos, tenho muito medo do que irá acontecer com minha carreira quando eu tiver 60 anos de idade. Ou crio uma fábrica de artigos produzidos por orientandos e jogo no lixo minha concepção de autoria, ensino e sobre como lidar com meus alunos, ou sou sumariamente excluído da pós-graduação stricto senso. E, aqui, gostaria de prestar minha solidariedade a professores que foram produtivos de fato durante toda a sua vida e que, depois dos 60 anos, estão sendo escorraçados das pós-graduações do Brasil. Estamos privando nossos alunos do convívio com pessoas que construíram o que somos hoje e deixando de lado qualquer senso de história do campo.

Dito isso, faz algum sentido ainda discutir o produtivismo? O produtivismo acadêmico impera. Viramos gestores de projetos, burocratas de papers. A formação vem sendo cada vez mais esquecida, o objetivo é produzir, ainda que sem formação ou conteúdo. Muitos estão adoecendo com este sistema. Mede-se, apenas, quantidade de produção acadêmica. A qualidade ficou de lado. Há dez anos o problema está claramente diagnosticado. As explicações também estão dadas: invasão do gerencialismo na produção científica, cópia mal feita de modelos estrangeiros, sem falar da Capes, o nosso grande bode expiatório. O que mais há para ser dito a respeito disso?

No entanto, não à toa este tema foi escolhido para esta conversa. Se você está lendo este texto é porque ainda não se encontrou uma solução para o problema. Na verdade, precisamos começar a pensar em maneiras de enfrentar o produtivismo. Maneiras de danificar este sistema, este mecanismo de controle. Já passou da hora de resistirmos.

Após ler Foucault (ALCADIPANI, 2005), aprendemos que sistemas de controle existem e permanecem pelo fato de não serem absolutos e não serem meramente opressores. Se o produtivismo está tão em voga é porque: ele atende a interesses; ele serve para alguém; ele tem ambiguidades que lhe permitem existir; ele oferece esperanças às pessoas. Nenhuma forma de dominação que seja apenas opressiva perdura. $\mathrm{O}$ produtivismo é útil ao fazer uma suposta "objetificação" da mensuração da "qualidade" de um pesquisador. Ele coloca um critério aparentemente claro: quem mais produz, melhor é. Ele atende, antes de mais nada, ao ego dos pesquisadores que querem ver seu nome no topo da lista dos mais produtivos. Permite que programas de pós-graduação e professores sejam avaliados e fomenta a ilusão de reputação para os "produtivos". E, o pior, permite que muitos professores não realmente pesquisadores, burocratas sem consistência, permaneçam no sistema com uma aura de competência acadêmica. Criamos um mecanismo de controle que está totalmente desvirtuado e gerando excrescências, mas que é diariamente alimentado por cada um de nós quando mandamos vários artigos para periódicos, quando pedimos aos nossos alunos que façam artigos antes de terem conhecimento do tema e por aí afora. O produtivismo apenas se reproduz na medida em que cada um de nós o faz existir no nosso cotidiano.

Não acreditamos que um sistema se rompa de uma hora para outra, sem que nada seja feito por aqueles que o sustentam, ou seja, nós os pesquisadores. Precisamos agir, e rápido, contra o produtivismo. E o que podemos fazer? Consideramos que o melhor a ser feito é perturbar. Gerar pequenas ou grandes perturbações no sistema, gerar mal-estar, incômodo, desconforto, escancarando o lado opressor desta situação, recusando-nos a nos submeter a esta lógica e, se preciso, pagando o preço por isso.

Primeiro, deveríamos nos recusar a pedir que nossos alunos de mestrado/doutorado escrevam artigos quando não possuem formação para tal - que nada têm a ver com seus interesses. Deveríamos lhes dizer que, durante o curso, precisam estudar, ler a respeito do tema que querem pesquisar e que só vão escrever algo quando tiverem bastante conhecimento sobre o assunto. Não deveríamos pedir para nossos alunos que escrevam um paper por disciplina e, sim, desencorajá-los a mandar artigos que não estejam relacionados 
com temas que eles verdadeiramente pesquisam para os congressos científicos. A pós-graduação deve servir para formar. Se a dissertação ficar boa, aí, sim, os encorajamos a escrever textos.

Segundo: nos recusar a colocar o nome em trabalhos que não escrevemos e para os quais não demos nenhuma contribuição. Que fique claro, de uma vez por todas, o que significa autoria acadêmica precisamos parar de aceitar que nossos colegas explorem os alunos. Hoje a produção acadêmica brasileira em Administração é feita em larga medida por alunos. Os professores precisariam voltar a pesquisar e a escrever de fato. Teríamos, sim, de mostrar nosso desagrado com os colegas que fazem sua produção acadêmica fundamentada unicamente em seus alunos.

Terceiro: nos solidarizar com aqueles que, apesar de terem uma história acadêmica sólida, são excluídos da pós-graduação. Tempos atrás, o Professor Ibarra Colado passou por um problema em sua universidade no México e acadêmicos do mundo todo escreveram para o diretor da universidade mostrando sua preocupação com o fato. Temos de nos mobilizar contra os absurdos que estão sendo feitos contra nossos colegas e também para que a Capes leve senioridade em consideração e valorize programas de pós que possuam figura ilustres de nossa área como Pedro Lincoln, João Gualberto, Carlos Osmar Betero, Sylvia Vergara, Valmiria Piccini, entre outros.

Quarto: fugir do discurso fácil de que a Capes é o demônio. Deveríamos nos recusar a produzir artigos somente pela produção. A Capes exige-nos apenas 50 pontos por ano, não mais que isso. Mas o fato de a Capes não ser o demônio está longe de significar que a sua forma de avaliar é correta. O sistema está falido, caduco e precisa ser reformulado para valorizar a boa formação dos alunos e a produção acadêmica de qualidade.

Quinto: exigir que nossos periódicos façam boas avaliações de nossos artigos e sejam geridos, de fato, por acadêmicos e não pelas secretárias. Os editores precisam editar. Um bom processo de avaliação é fundamental para o crescimento acadêmico, assim como políticas editoriais sérias. Hoje a discussão a respeito dos periódicos nacionais, em lugar de tratar de questões substantivas de produção acadêmica, está voltada para aspectos burocráticos da produção científica. Temos de parar com a proliferação de periódicos e de discutir fatores de impacto, indexadores e burocracias afins. O que é um bom artigo, o que é uma boa avaliação, o que é um bom periódico são questões substantivas que a burocracia está deixando de lado.

Sexto: precisamos de associações de pesquisadores que representem os nossos interesses. A Anpad, como associação de programas, está com sérios problemas e precisa de uma renovação urgente - sequer consegue produzir eventos interessantes, tampouco nos representar diante de nossas agências reguladoras. É preciso termos sociedades de pesquisadores que levem em conta nossas necessidades e demandas em termos de representação e de realização de eventos. A Anpad deve permanecer forte, mas precisa de lideranças que escutem a comunidade, dialoguem com todos e aceitem as opiniões divergentes e contrárias. Precisamos demonstrar nosso descontentamento com a maneira como as coisas estão hoje na nossa associação. Uma Anpad fraca enfraquece a todos nós e é nossa responsabilidade cobrar mudanças.

Sétimo: não assumir cargos administrativos apenas para termos poder. Aqueles que têm amor ao cargo e ao poder pelo poder são levados a manter o sistema que está aí, pois são privilegiados por ele. É fundamental ter coragem para recusar o papel de "marionete" do sistema acadêmico vigente. Assumir cargos para privilegiar os já privilegiados e manter as práticas que existem é um desserviço à nossa comunidade acadêmica.

Já passou da hora de assumirmos nossas responsabilidades como pesquisadores e de pararmos de reclamar pelos cantos. Temos de afrontar o produtivismo de frente e perturbar o máximo que pudermos. Se não fizermos isso, deixaremos que o ideal de ser acadêmico para produzir conteúdo que faça sentido e de ter orgulho pelos alunos que formamos seja massacrado pela burrice de uma academia que está virando uma grande fábrica de sardinha em lata. 


\section{Referências}

ALCADIPANI, R. Michel Foucault, Poder e a Análise das Organizações. Rio de Janeiro: Editora da FGV, 2005.

Academia e a fábrica de sardinha em lata. Organização \& Sociedade, Salvador, UFBA, v. 18, n. 54, p. 345$\overline{348, \text { abr./jul. } 2011 .}$

ALCADIPANI, R.; BRESLER, R. A McDonaldização do Ensino. Carta Capital, 10 de Maio. São Paulo: Ed. 133, 1999.

POWER, M. The Audit Society. Oxford: Oxford University Press, 1997. 